\title{
Antioxidant intake from diet and supplements and risk of digestive cancers in middle-aged adults: results from the prospective NutriNet-Santé cohort
}

\author{
Manon Egnell ${ }^{1}$, Philippine Fassier ${ }^{1 *}$, Lucie Lécuyer ${ }^{1}$, Rebeca Gonzalez ${ }^{1}$, Laurent Zelek ${ }^{1,2}$, \\ Marie-Paule Vasson ${ }^{3}$, Serge Hercberg ${ }^{1,4}$, Paule Latino-Martel ${ }^{1}$, Pilar Galan ${ }^{1}$, Nathalie Druesne-Pecollo ${ }^{1}$, \\ Mélanie Deschasaux ${ }^{1}$ and Mathilde Touvier ${ }^{1}$ \\ ${ }^{1}$ Nutritional Epidemiology Research Team (EREN), Sorbonne Paris Cité Epidemiology and Statistics Research Center (CRESS), \\ Institute for Health and Medical Research (Inserm, U1153), Institut National de la Recherche Agronomique (INRA, U1125), \\ Conservatoire National des Arts et Métiers (CNAM), University Paris 13, 93000 Bobigny, France \\ ${ }^{2}$ Oncology Department, Avicenne Hospital, Assistance Publique - Hôpitaux de Paris (AP-HP), 93000 Bobigny, France \\ ${ }^{3}$ UFR Pharmacie, UMR 1019, Centre de Recherches en Nutrition Humaine (CRNH) Auvergne, Centre Jean-Perrin, Clermont \\ UniversitéAuvergne, Institut National de la Recherche Agronomique (INRA), CHU Gabriel-Montpied, Unité de Nutrition, 63009 \\ Clermont-Ferrand, France \\ ${ }^{4}$ Public Health Department, Avicenne Hospital, Assistance Publique - Hôpitaux de Paris (AP-HP), 93000 Bobigny, France \\ (Submitted 3 March 2017 - Final revision received 4 July 2017 - Accepted 1 August 2017 - First published online 20 September 2017)
}

\section{Abstract}

Experimental studies suggest beneficial effects of antioxidants in digestive cancer prevention. However, epidemiological results are contrasting and few studies quantitatively assessed supplemental intake. This study aimed at investigating the associations between antioxidant intakes (dietary, supplemental and total) and digestive cancer risk. This prospective study included 38812 middle-aged subjects ( $\geq 45$ years) from the NutriNet-Santé cohort (2009-2016). Dietary data were collected using repeated 24 h records. A specific questionnaire assessed dietary supplement use over a $12-$ month period. A composition database of about 8000 dietary supplements was developed. Associations between continuous and sex-specific quartiles of vitamins $\mathrm{C}$ and $\mathrm{E}, \beta$-carotene and Se intakes and digestive cancer risk were characterised using multivariable Cox proportional hazard models. A total of 167 incident digestive cancers (120 colorectal, twenty-six pancreatic, nine oesophagus, seven stomach and five liver) were diagnosed during follow-up investigation. Dietary (hazard ratios $\left.(\mathrm{HR})_{\mathrm{Q} 4} v \cdot \mathrm{Q} 1=0 \cdot 56 ; 95 \% \mathrm{CI} 0 \cdot 34,0 \cdot 91, P_{\text {trend }}=0 \cdot 01\right)$ and total $\left(\mathrm{HR} \mathrm{Q}_{4} v \cdot \mathrm{Q} 1=0 \cdot 51\right.$; $95 \%$ CI $\left.0.30,0.84, P_{\text {trend }}=0.008\right)$ vitamin C intakes, dietary $\left(\mathrm{HR}_{\mathrm{Q} 4} v \cdot \mathrm{Q} 1=0.56 ; 95 \%\right.$ CI $\left.0.34,0.92, P_{\text {trend }}=0.005\right)$ and total $(\mathrm{HR} \mathrm{Q} v . \mathrm{Q} 1=0.58$; $95 \%$ CI 0.36, 0.94, $\left.P_{\text {trend }}=0.003\right)$ vitamin E intakes, and dietary $\left(\mathrm{HR}_{\mathrm{for}}\right.$ an increment of $\left.10 \mu \mathrm{g} / \mathrm{d}=0.92 ; 95 \% \mathrm{CI} 0.85,1 \cdot 00, P=0.04\right)$ and total $\left(\mathrm{HR}_{\mathrm{for}}\right.$ an increment of $10 \mu \mathrm{g} / \mathrm{d}=0.92 ; 95 \% \mathrm{CI} 0.86,0.99, P=0.03)$ Se intakes were associated with a decreased digestive cancer risk. Statistically significant interactions were observed between dietary and total Se intakes and alcohol consumption as well as between total vitamin E intake and smoking status. This prospective cohort study with quantitative assessment of supplemental intakes suggests a potential protective effect of several antioxidants (vitamins $\mathrm{C}$ and $\mathrm{E}$ and $\mathrm{Se}$ ) on digestive cancer risk, and a modulation of some of these relationships by alcohol consumption and smoking status.

Key words: Antioxidants: Diet: Dietary supplements: Prospective cohorts: Digestive cancers

According to the WHO, colorectal cancer is the third most common cancer in the world with approximately 1.36 million new cases diagnosed in $2012^{(1)}$. Although less frequent, other digestive cancers represented about 952000 (stomach), 782000 (liver), 456000 (pancreas) and 338000 (oesophagus) new cases in $2012^{(1)}$. A public health challenge lies in the identification of efficient modifiable risk factors to foster the prevention of these multifactorial pathologies. For many years now, experimental studies have strongly suggested a protective effect of antioxidants on digestive cancer risk, through the neutralisation of free radicals that damage cellular components, particularly DNA, and trigger carcinogenesis ${ }^{(2)}$.
However, epidemiological evidence of digestive cancer prevention through antioxidants is still lacking. Several metaanalyses of placebo-controlled randomised trials showed null results $^{(2-4)}$. For instance, a 2013 meta-analysis including twenty trials did not observe any significant association for colorectal cancer $^{(3)}$. However, even if randomised trials are particularly adapted to provide evidence regarding causality of the studied associations, they often reflect non-physiological experimental situations (very high doses, isolated nutrients, etc.). Thus, observational studies provide complementary information as they are based on real-life exposures in terms of nutrient associations, sources (dietary or supplemental) and doses.

Abbreviations: HR, hazard ratio; IPAQ, International Physical Activity Questionnaire.

* Corresponding author: P. Fassier, fax +33 1483889 31, email p.fassier@eren.smbh.univ-paris13.fr 
Results of observational prospective studies regarding antioxidant intake and digestive cancer risk are contrasted and, so far, the World Cancer Research Fund and the American Institute for Cancer Research judged the level of proof as 'limitednon-conclusion' for all studied associations ${ }^{(5-9)}$. Since then, several original prospective cohort studies and meta-analyses have been published, some of which demonstrated null results $^{(10-12)}$, but others showed significant inverse associations $^{(13-16)}$. For instance, a 2015 meta-analysis of seventy-six cohort studies showed a significant inverse association between dietary vitamin $\mathrm{C}$ intake and stomach cancer risk ${ }^{(16)}$.

In addition, individual factors such as smoking status or alcohol intake may modulate these associations, as demonstrated for $\beta$-carotene, which interacts with tobacco, on lung and gastric cancer risk ${ }^{(17,18)}$. Nevertheless, very few prospective studies investigated the interactions between other antioxidants and smoking status ${ }^{(19-23)}$ or alcohol intake ${ }^{(21,23,24)}$ on digestive cancer risk.

Besides, a given nutrient may have differential effects according to its vector (food or supplement). However, a relatively limited number of observational prospective studies specifically investigated the associations between antioxidant supplement use and digestive cancer risk ${ }^{(10,15,19,20,25,26)}$ and, to our knowledge, few of them took into account quantitative supplement doses ${ }^{(10,19)}$. Dietary supplement use is constantly increasing in occidental countries and their omission in many epidemiological studies may lead to important classification bias ${ }^{(27)}$.

Thus, this study aimed at investigating the associations between dietary, supplemental and total intakes of antioxidants (vitamins $\mathrm{C}$ and $\mathrm{E}, \beta$-carotene and $\mathrm{Se}$ ) and digestive cancer risk in middle-aged adults, and their potential modulation by smoking status and alcohol intake.

\section{Methods}

\section{Study population}

The NutriNet-Santé study is an ongoing web-based French cohort study launched in 2009 with the objective of investigating the associations between nutrition and health as well as the determinants of dietary behaviours and nutritional status. This cohort has been previously described in detail ${ }^{(28)}$. Participants aged over 18 years with access to the Internet are recruited through vast multimedia campaigns. All questionnaires are completed online using a dedicated website (www.etude-nutrinet-sante.fr). The NutriNet-Santé study is conducted according to the Declaration of Helsinki guidelines. It was approved by the Institutional Review Board of the French Institute for Health and Medical Research (IRB, Inserm no. 0000388FWA00005831) and the 'Commission Nationale de l'Informatique et des Libertés' (no. 908450/n909216). Electronic informed consent was obtained from each participant (EudraCT no. 2013-000929-31).

\section{Data collection}

At inclusion, participants completed a set of five questionnaires related to sociodemographic and lifestyle characteristics ${ }^{(29)}$ (e.g. occupation, educational level, smoking status, number of children), anthropometric measurements ${ }^{(30,31)}$ (e.g. height, weight), dietary intakes (see below), physical activity (validated International Physical Activity Questionnaire (IPAQ) questionnaire) ${ }^{(32)}$ and health status (e.g. personal and family history of diseases). Physical activity was measured using the short version of the IPAQ questionnaire ${ }^{(32)}$. Frequency and duration of participation in vigorous, moderate-intensity and walking activities during a weekday were assessed with a set of seven questions. Time spent in each type of activity was calculated in $\mathrm{h} /$ min per week. After multiplying the number of hours per week of each type of activity by an average metabolic cost $(\mathrm{MET})^{(33)}$, an energy expenditure indicator was obtained and expressed in MET-h/week. The sum of the three activity scores provided an indicator of total physical activity. These calculations, as well as the classification of individuals into the three IPAQ categories have been computed according to the official IPAQ guidelines, including truncation to avoid extreme outliers (e.g. minutes at each intensity level exceeding 180/d were truncated to 180 to avoid extreme outliers).

Dietary data. Usual dietary intake was assessed every 6 months through a series of three non-consecutive validated web-based self-administered 24-h dietary records, randomly assigned over a 2 -week period ( 2 weekdays and 1 weekend day) ${ }^{(34-36)}$. Mean dietary intakes during the 1 st year of the study were considered as baseline dietary intake in this prospective analysis. Participants used a dedicated interface of the study website to declare all foods and beverages consumed during a 24-h period: three main meals (breakfast, lunch and dinner) and any other eating occasion. Portion sizes were estimated using validated photographs $^{(37)}$. The mean daily energy, alcohol and nutrient intake was estimated using a published French food composition table (>3300 items) $)^{(38)}$. Amounts consumed from composite dishes were estimated using French recipes validated by food and nutrition professionals. Dietary under-reporting was identified on the basis of the method proposed by Black, using the BMR and Goldberg cut-off point, and under-reporters of energy were excluded $^{(39)}$. The present study focused on intakes of vitamin $\mathrm{C}$, vitamin $\mathrm{E}, \beta$-carotene and Se.

Dietary supplement use. At 2 months after inclusion, participants were invited to complete a web-based self-administered questionnaire regarding dietary supplement use ${ }^{(40)}$. In the questionnaire, participants were asked whether they took any supplement during the past 12 months (at least once). They had to specify the name and the brand of the dietary supplement (open-ended questionnaire), the form used, the number of days of consumption and the number of units generally used when they consumed the supplement. The average daily intake of dietary supplements during the last 12 months has been assessed for each subject, using a composition database containing about 8000 dietary supplements declared by the participants of the NutriNet-Santé study. In the present study, 'true' dietary supplements and medicinal supplements (supplements considered as pharmaceutical products in France, and mainly composed of vitamins and minerals) were both considered as dietary supplements. However, for each nutrient, participants 
whose supplemental intake exceeded the 99th percentile by using a medicinal supplement were excluded.

\section{Case ascertainment}

Participants self-declared health events through the yearly health status questionnaire, a specific check-up questionnaire for health events (every 3 months) or at any time through an interface on the study website. Following this declaration, participants were invited to send their medical records (diagnosis, hospitalisation, etc.) and, if necessary, the study physicians contacted the participants' physician or the medical structures to collect additional information. Next, data were reviewed by an independent physician expert committee for the validation of major health events. Cancer cases were classified using the International Chronic Diseases Classification, 10th Revision, Clinical Modification ${ }^{(41)}$. In this study, all first primary colon, rectum, pancreatic, oesophagus, stomach and liver cancers diagnosed between inclusion and April 2016 were considered as cases.

\section{Statistical analyses}

A total of 73773 participants provided at least three valid 24-h dietary records during the 1 st year of follow-up investigation and answered the dietary supplement questionnaire. Participants aged under 45 years were excluded ( $n$ 34961) because of a low susceptibility to develop digestive cancer ${ }^{(42)}$. Thus, 38812 subjects were included in the analyses. For all covariates except physical activity, $\leq 5 \%$ of values were missing and were imputed to the modal value. For physical activity ( $n 4629$ missing values), a 'missing class' was introduced into the models. Dietary intakes of vitamins $\mathrm{C}$ and $\mathrm{E}, \beta$-carotene and Se were coded as continuous and sex-specific quartiles. For each nutrient, supplemental intakes were coded as users or non-users, and as a four-category variable: non-users and sex-specific tertiles of supplemental intake in users. Total (dietary + supplemental) intakes were coded as continuous and sex-specific quartiles.

Associations between dietary, supplemental, and total intake of vitamin $\mathrm{C}$, vitamin $\mathrm{E}, \beta$-carotene and Se and digestive cancer risk were characterised (by means of hazard ratio (HR) and 95\% CI) using multivariable Cox proportional hazard models with age as the primary time variable. We verified that the assumptions of proportionality were satisfied through examination of the $\log -\log$ (survival) $v$. log-time plots. Participants contributed person-time to the Cox model until the date of cancer diagnosis, the date of the last completed questionnaire, the date of death or April 2016, whichever occurred first.

Models were adjusted for age (time-scale), BMI $\left(\mathrm{kg} / \mathrm{m}^{2}\right.$, continuous, BMI was calculated by dividing the weight (in $\mathrm{kg}$ ) by the square of the height (in $\mathrm{m}$ )), height ( $\mathrm{cm}$, continuous), physical activity (high, moderate and low, computed following IPAQ recommendations ${ }^{(32)}$ ), smoking status (never smokers, former smokers and current smokers), number of cigarette packs per year (in former and current smokers, continuous), number of dietary records (continuous), alcohol intake $(\mathrm{g} / \mathrm{d}$, continuous), energy intake (without alcohol, g/d, continuous), family history of cancer (yes or no) and educational level (<high-school degree, $<2$ years after high-school degree and $\geq 2$ years after high-school degree). Further adjustments for birth year, fruit and vegetable intakes and time spent sitting, have been tested. Tests for linear trends were performed across categories with the use of the ordinal value of the corresponding variable.

In exploratory analyses, the interactions between dietary, supplemental and total intake of each antioxidant and the following potential modifiers were tested by introducing the product of the two variables into Cox models: smoking status (current smokers or non- or former smokers), alcohol intake $(</ \geq$ to the sex-specific population median, i.e. $3.6 \mathrm{~g} / \mathrm{d}$ in women and $12.4 \mathrm{~g} / \mathrm{d}$ in men), family history of cancer (yes or no) and sex. Stratified analyses were performed when appropriate.

A $P$ value $\leq 0.05$ was considered statistically significant. All analyses were carried out using SAS software (version 9.4; SAS Institute, Inc.).

\section{Results}

The study lasted for 7 years, between May 2009 and April 2016. A total of 155527 person-years were followed up and 167 incident digestive cancers were diagnosed, including 120 colorectal, twenty-six pancreatic, nine oesophagus, seven stomach and five liver cancers. The mean age at diagnosis was $57 \cdot 1$ (SD 7.4) years and the mean baseline-to-diagnosis time was $2 \cdot 8$ (SD 1.8) years. The mean number of dietary records per subject over their 1st year of follow-up investigation was 4.8 (SD 1.6). The baseline characteristics of participants are described in Table 1 . The proportions of dietary supplement users were $15.9 \%$ for vitamin C, $12.7 \%$ for vitamin E, $3.3 \%$ for $\beta$-carotene and $8.6 \%$ for Se.

Table 2 displays the associations between dietary, supplemental and total intake of vitamins $\mathrm{C}$ and $\mathrm{E}, \beta$-carotene and $\mathrm{Se}$ and digestive cancer risk. Dietary $\left(\mathrm{HR}_{\mathrm{Q} 4} v \cdot \mathrm{Q}_{1}=0.56 ; 95 \% \mathrm{CI}\right.$ $\left.0.34,0.91, P_{\text {trend }}=0.01\right)$ and total $\left(\mathrm{HR}_{\mathrm{Q} 4} v \cdot \mathrm{Q} 1=0.51 ; 95 \% \mathrm{CI}\right.$ $\left.0.30,0.84, P_{\text {trend }}=0.008\right)$ vitamin $\mathrm{C}$ intakes were inversely associated with digestive cancer risk. Dietary $\left(\mathrm{HR}_{\mathrm{Q} 4} v \cdot \mathrm{Q} 1=0 \cdot 56\right.$; $95 \%$ CI $\left.0.34,0.92, P_{\text {trend }}=0.005\right)$ and total $\left(\mathrm{HR}_{\mathrm{Q} 4} v \cdot \mathrm{Q}_{1}=0.58\right.$; $95 \%$ CI 0.36, 0.94, $\left.P_{\text {trend }}=0.003\right)$ vitamin $\mathrm{E}$ intakes were inversely associated with digestive cancer risk. Dietary

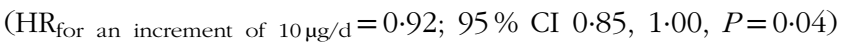

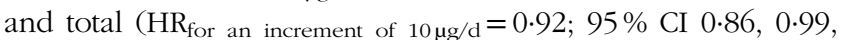
$P=0.03)$ Se intakes were also associated with a decreased digestive cancer risk, but only when intakes were coded as continuous variables. No significant association was found between digestive cancer risk and supplemental intakes.

In exploratory analyses, statistically significant interactions between alcohol intake and dietary and total Se intakes were observed ( $P=0.02$ for dietary Se, $P=0.01$ for total Se, Table 3). In stratified analyses, dietary and total intakes of Se were associated with a decreased digestive cancer risk among participants with alcohol intake above the sex-specific population

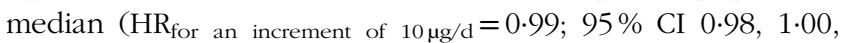

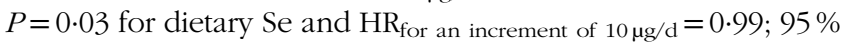
CI $0.98,1.00, P=0.02$ for total Se), whereas these associations were not statistically significant in participants with non-to-low 
Table 1. Baseline characteristics of the study population ( $n$ 38812), NutriNet-Santé Cohort, France, 2009-2016

(Numbers and percentages; mean values and standard deviations)

\begin{tabular}{|c|c|c|c|c|}
\hline & $n$ & $\%$ & Mean & SD \\
\hline Age (years) & & & $57 \cdot 1$ & 7.4 \\
\hline \multicolumn{5}{|l|}{ Educational level } \\
\hline$<$ High-school degree & 11532 & 29.7 & & \\
\hline $\begin{array}{l}\geq \text { High-school degree to }<2 \text { years after } \\
\text { high-school degree }\end{array}$ & 6309 & $16 \cdot 3$ & & \\
\hline$\geq 2$ years after high-school degree & 20971 & 54.0 & & \\
\hline \multicolumn{5}{|l|}{ Smoking status } \\
\hline Non-smokers & 17030 & 43.9 & & \\
\hline Former smokers & 17455 & $45 \cdot 0$ & & \\
\hline Current smokers & 4327 & $11 \cdot 1$ & & \\
\hline Number of cigarette packs per year* & & & 255.9 & $222 \cdot 8$ \\
\hline \multicolumn{5}{|l|}{ Physical activity $\dagger$} \\
\hline Low & 13849 & 35.7 & & \\
\hline Moderate & 13420 & 34.6 & & \\
\hline High & 6914 & $17 \cdot 8$ & & \\
\hline BMI $\left(\mathrm{kg} / \mathrm{m}^{2}\right)$ & & & 24.7 & 4.5 \\
\hline Height (cm) & & & $166 \cdot 3$ & 8.3 \\
\hline Energy intake without alcohol $(\mathrm{kJ} / \mathrm{d})$ & & & 7563.4 & $1859 \cdot 4$ \\
\hline Energy intake without alcohol (kcal/d) & & & $1807 \cdot 7$ & 444.4 \\
\hline Alcohol intake $(\mathrm{g} / \mathrm{d})$ & & & $9 \cdot 81$ & $13 \cdot 2$ \\
\hline Family history of cancer (yes) $\ddagger$ & 19794 & $51 \cdot 0$ & & \\
\hline Dietary intake of vitamin C (mg/d) & & & $119 \cdot 0$ & 66.9 \\
\hline Supplemental intake of vitamin $C(\mathrm{mg} / \mathrm{d}) \S$ & 8754 & $15 \cdot 9$ & $55 \cdot 6$ & $155 \cdot 3$ \\
\hline Total intake of vitamin C $(\mathrm{mg} / \mathrm{d})$ & & & 127.4 & $92 \cdot 9$ \\
\hline Dietary intake of vitamin $E(\mathrm{mg} / \mathrm{d})$ & & & 11.8 & 4.7 \\
\hline Supplemental intake of vitamin $E(\mathrm{mg} / \mathrm{d}) \S$ & 7028 & $12 \cdot 7$ & $7 \cdot 7$ & $28 \cdot 2$ \\
\hline Total intake of vitamin $E(\mathrm{mg} / \mathrm{d})$ & & & $12 \cdot 8$ & 11.5 \\
\hline Dietary intake of $\beta$-carotene $(\mathrm{mg} / \mathrm{d})$ & & & 3771.0 & $2531 \cdot 0$ \\
\hline Supplemental intake of $\beta$-carotene $(\mathrm{mg} / \mathrm{d}) \S$ & 1837 & 3.3 & $1544 \cdot 5$ & $3367 \cdot 0$ \\
\hline Total intake of $\beta$-carotene $(\mathrm{mg} / \mathrm{d})$ & & & 3824.5 & $2634 \cdot 2$ \\
\hline Dietary intake of $S e(\mu \mathrm{g} / \mathrm{d})$ & & & $70 \cdot 8$ & $26 \cdot 0$ \\
\hline Supplemental intake of $\mathrm{Se}(\mu \mathrm{g} / \mathrm{d}) \S$ & 4763 & 8.6 & $15 \cdot 7$ & 23.9 \\
\hline Total intake of $\mathrm{Se}(\mu \mathrm{g} / \mathrm{d})$ & & & $72 \cdot 2$ & $27 \cdot 4$ \\
\hline
\end{tabular}

* Among current and former smokers.

† From the validated International Physical Activity Questionnaire. The highest category corresponds to participants who practiced vigorous-intensity activity on at least $3 \mathrm{~d}$ during the week and accumulating at least 1500 MET-min/week, or $7 \mathrm{~d}$ of any combination of walking, moderate-intensity or vigorous-intensity activities achieving a minimum of at least $3000 \mathrm{MET}-\mathrm{min} /$ week. The category of moderate physical activity corresponds to any one of the following three criteria: 3 or more days of vigorous activity of at least $20 \mathrm{~min} / \mathrm{d}$ or 5 or more days of moderate-intensity activity or walking of at least $30 \mathrm{~min} / \mathrm{d}$, or 5 or more days of any combination of walking, moderate-intensity or vigorous-intensity activities achieving a minimum of at least $600 \mathrm{MET}-\mathrm{min} / \mathrm{week}$. The lowest category concerns participants with the lowest level of physical activity, who did not meet criteria of the categories 'high' or 'moderate'. Data available for 34183 subjects.

$\ddagger$ In first-degree relatives.

$\S$ Users of the corresponding supplement, and mean daily intake among users only.

alcohol consumption. A statistically significant interaction between smoking status and dietary vitamin $\mathrm{E}$ intake was also observed $(P=0 \cdot 01$, Table 4$)$. In stratified analyses, dietary vitamin $\mathrm{E}$ intake was associated with a decreased digestive cancer risk among non-smokers and former smokers $\left(\mathrm{HR}_{\text {for an increment of } 1 \mathrm{mg} / \mathrm{d}}=0.94 ; 95 \% \mathrm{CI} 0.89,0.98, P=0.007\right)$, whereas no association was observed in current smokers. No interaction was observed between $\beta$-carotene and vitamin $\mathrm{C}$ intakes and alcohol intake or smoking status (all $P$ value $>0 \cdot 10$ ). Further, no interaction was detected between family history of cancer and any type of intake (all $P>0.05$, data not tabulated). No interaction between vitamin $\mathrm{C}$, vitamin $\mathrm{E}$ and $\beta$-carotene intakes and sex was found. However, an interaction has been observed between sex and dietary and total Se intakes
$\left(P_{\text {interaction }}=0.09\right.$ and 0.06, respectively). Dietary and total Se intakes were inversely associated with digestive cancer risk in men $\left(\mathrm{HR}_{\mathrm{Q} 4}\right.$ v. Q1 $=0.47 ; 95 \%$ CI $0.24-0.92, P_{\text {trend }}=0.05$ and $\mathrm{HR}_{\mathrm{Q} 4 v \cdot \mathrm{Q} 1}=0 \cdot 45 ; 95 \% \mathrm{CI} 0 \cdot 23-0 \cdot 88, P_{\text {trend }}=0 \cdot 03$, respectively), but not in women $\left(P_{\text {trend }}=0.7\right.$ and 0.5 , respectively).

Similar results were observed when cancer cases diagnosed during their 1st year of follow-up investigation were excluded from the analysis (134 cases/38812 non-cases included, data not shown) and when models were adjusted for birth year $\left(\mathrm{HR}_{\mathrm{Q} 4} v \cdot \mathrm{Q} 1=0.55 ; 95 \% \mathrm{CI} 0.34,0.90, P_{\text {trend }}=0.01\right.$ for dietary and $\mathrm{HR}_{\mathrm{Q} 4} v \cdot \mathrm{Q}_{1}=0.51 ; 95 \%$ CI $0.30,0.84, P_{\text {trend }}=0.007$ for total intakes of vitamin $\mathrm{C}, \mathrm{HR}_{\mathrm{Q} 4} v . \mathrm{Q}_{1}=0.56 ; 95 \% \mathrm{CI} 0.34$, $0.91, P_{\text {trend }}=0.005$ for dietary and $\mathrm{HR}_{\mathrm{Q} 4} v . \quad \mathrm{Q}_{1}=0.58 ; 95 \%$ CI $0.36,0.94, P_{\text {trend }}=0.003$ for total intakes of vitamin $\mathrm{E}$, $\mathrm{HR}_{\text {for an increment of } 10 \mu \mathrm{g} / \mathrm{d}}=0.92 ; 95 \% \mathrm{CI} 0.85,1 \cdot 00, P=0.04$ for

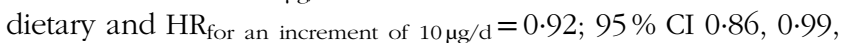
$P=0.03$ for total intakes of Se) (data not tabulated). Similar trends were found when models were adjusted for fruit and vegetable intakes $\left(\mathrm{HR}_{\mathrm{Q} 4}\right.$ v. Q1 $=0.56 ; 95 \%$ CI $0.34,0.91$, $P_{\text {trend }}=0.01$ for dietary and $\mathrm{HR}_{\mathrm{Q} 4} v \cdot \mathrm{Q} 1=0.55 ; 95 \%$ CI $0.31,0.97$, $P_{\text {trend }}=0.04$ for total intakes of vitamin C, $\mathrm{HR}_{\mathrm{Q} 4} v \cdot \mathrm{Q} 1=0.60$; $95 \% \mathrm{CI} 0 \cdot 36,1 \cdot 01, P_{\text {trend }}=0.02$ for dietary and $\mathrm{HR}_{\mathrm{Q} 4 v . \mathrm{Q} 1}=0.62$; $95 \%$ CI $0.38,1.02, P_{\text {trend }}=0.01$ for total intakes of vitamin E,

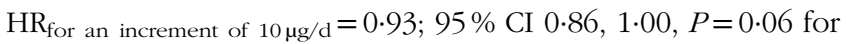

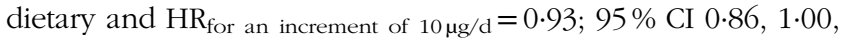
$P=0.05$ for total intakes of Se). Similar results were observed when models were adjusted for time spent sitting $\left(\mathrm{HR}_{\mathrm{Q} 4} v\right.$. $\mathrm{Q} 1=0.56 ; 95 \%$ CI $0.34,0.91, P_{\text {trend }}=0.01$ for dietary and $\mathrm{HR}_{\mathrm{Q} 4} v$. $\mathrm{Q}_{1}=0.51 ; 95 \%$ CI $0.31,0.85, P_{\text {trend }}=0.008$ for total intakes of vitamin $\mathrm{C}, \mathrm{HR}_{\mathrm{Q} 4} v \cdot \mathrm{Q} 1=0.47 ; 95 \%$ CI $0 \cdot 27,0.81, P_{\text {trend }}=0.001$ for dietary and $\mathrm{HR}_{\mathrm{Q} 4} v \cdot \mathrm{Q} 1=0.50 ; 95 \%$ CI $0.30,0.85, P_{\text {trend }}=0.001$ for total intakes of vitamin E, $\mathrm{HR}_{\mathrm{for}}$ an increment of $10 \mu \mathrm{g} / \mathrm{d}=0.93 ; 95 \%$ CI $0.86,1.01, P=0.09$ for dietary and $\mathrm{HR}_{\mathrm{for}}$ an increment of $10 \mathrm{\mu g} / \mathrm{d}=$ 0.93; $95 \%$ CI 0.86, 1.01, $P=0.08$ for total intakes of Se).

When analyses were restricted to colorectal cancers (120 cases, online Supplementary Table S1), results were unchanged for vitamin $\mathrm{E}\left(\mathrm{HR}_{\mathrm{Q} 4} v\right.$. Q1 $=0.42 ; 95 \% \mathrm{CI} 0 \cdot 23,0 \cdot 77, P_{\text {trend }}=0.003$ for dietary intake and $\mathrm{HR}_{\mathrm{Q} 4} v \cdot \mathrm{Q} 1=0.44 ; 95 \%$ CI $0 \cdot 24,0 \cdot 80$, $P_{\text {trend }}=0.002$ for total intake $)$ and borderline non-significant for vitamin $\mathrm{C}\left(\mathrm{HR}_{\mathrm{Q} 4} v \cdot \mathrm{Q} 1=0.66 ; 95 \% \mathrm{CI} 0.38,1 \cdot 16, P_{\text {trend }}=0.09\right.$ for dietary intake and $\mathrm{HR}_{\mathrm{Q} 4}$ v. $\mathrm{Q} 1=0.60 ; 95 \%$ CI $0.33,1.09$, $P_{\text {trend }}=0.06$ for total intake).

\section{Discussion}

In this prospective cohort study, dietary and total intakes of vitamin $\mathrm{C}$, vitamin $\mathrm{E}$ and Se were associated with decreased digestive cancer risk. No association was observed with supplemental intakes. A modulation by alcohol intake and smoking status was suggested by statistically significant interactions: dietary and total intakes of Se were associated with decreased digestive cancer risk among subjects with alcohol intake above the sex-specific median, and total vitamin $\mathrm{E}$ intake was associated with decreased digestive cancer risk among never and former smokers.

Carcinogenesis involves complex pathways, among which oxidative processes play a central role. Therefore, a putative effect of antioxidants in the prevention of digestive cancers has 
Table 2. Associations between dietary, supplemental and total intakes of antioxidants and digestive cancer risk, from multivariable Cox proportional hazards models*, NutriNet-Santé Cohort ( $n$ 38812), France, 2009-2016

(Hazard ratios (HR) and 95\% confidence intervals)

\begin{tabular}{|c|c|c|c|c|c|c|c|c|c|c|c|c|c|c|c|}
\hline & & \multicolumn{4}{|c|}{ Dietary intake } & \multicolumn{5}{|c|}{ Supplemental intake } & \multicolumn{5}{|c|}{ Total intake } \\
\hline & & Cases/non-cases & $\mathrm{HR}$ & $95 \% \mathrm{Cl}$ & $P_{\text {trend }}$ & & Cases/non-cases & $\mathrm{HR}$ & $95 \% \mathrm{Cl}$ & $P_{\text {trend }}$ & & Cases/non-cases & $\mathrm{HR}$ & $95 \% \mathrm{Cl}$ & $P_{\text {trend }}$ \\
\hline \multirow[t]{5}{*}{ Vitamin C } & Continuous $†$ & $167 / 38611$ & 0.97 & $0.94,1.00$ & 0.05 & Users $v$. non-users & $22 / 5847$ & 0.90 & $0.57,1.42$ & 0.7 & Continuous & $167 / 38611$ & 0.97 & $0.94,0.99$ & 0.01 \\
\hline & Q1‡ & 45/9602 & 1 & Ref. & 0.01 & Non-users & $145 / 32764$ & 1 & Ref. & 0.3 & Q1 & $43 / 9599$ & 1 & Ref. & 0.008 \\
\hline & Q2 & $51 / 9646$ & 1.03 & $0.69,1.55$ & & T1 & $11 / 1874$ & 1.49 & $0 \cdot 81,2 \cdot 77$ & & Q2 & $53 / 9640$ & $1 \cdot 14$ & $0 \cdot 76,1 \cdot 71$ & \\
\hline & Q3 & $43 / 9669$ & 0.84 & $0.55,1.30$ & & T2 & $6 / 1999$ & 0.74 & $0.33,1.69$ & & Q3 & $46 / 9665$ & 0.95 & $0.62,1.46$ & \\
\hline & Q4 & 28/9694 & 0.56 & $0.34,0.91$ & & T3 & $5 / 1974$ & 0.56 & $0.23,1.36$ & & Q4 & $25 / 9707$ & 0.51 & $0.30,0.84$ & \\
\hline \multirow[t]{5}{*}{ Vitamin E } & Continuous & $167 / 38582$ & 0.95 & $0.91,1.00$ & 0.03 & Users $v$. non-users & $19 / 4988$ & 0.93 & $0.57,1.50$ & 0.8 & Continuous & $167 / 38582$ & 0.99 & $0.97,1.01$ & 0.5 \\
\hline & Q1 & $55 / 9599$ & 1 & Ref. & 0.005 & Non-users & $148 / 33594$ & 1 & Ref. & 0.7 & Q1 & $56 / 9591$ & 1 & Ref. & 0.003 \\
\hline & Q2 & 47/9632 & 0.80 & $0.54,1.20$ & & T1 & $6 / 1617$ & 0.99 & $0.43,2 \cdot 24$ & & Q2 & 49/9634 & 0.81 & $0.55,1 \cdot 21$ & \\
\hline & Q3 & $31 / 9678$ & 0.51 & $0.32,0.82$ & & T2 & $7 / 1738$ & 1.00 & $0.46,2.13$ & & Q3 & $25 / 9676$ & 0.40 & $0.24,0.66$ & \\
\hline & Q4 & $34 / 9673$ & 0.56 & $0.34,0.92$ & & T3 & $6 / 1633$ & 0.81 & $0.36,1.85$ & & Q4 & $37 / 9681$ & 0.58 & $0.36,0.94$ & \\
\hline \multirow[t]{5}{*}{$\beta$-Carotene } & Continuous & $167 / 38641$ & 1.00 & $1.00,1.00$ & 0.3 & Users $v$. non-users & $6 / 1337$ & $1 \cdot 16$ & $0.51,2.63$ & 0.7 & Continuous & $167 / 38641$ & 1.00 & $1.00,1.00$ & 0.3 \\
\hline & Q1 & $47 / 9603$ & 1 & Ref. & 0.04 & Non-users & $161 / 37304$ & 1 & Ref. & 0.5 & Q1 & $48 / 9602$ & 1 & Ref. & 0.06 \\
\hline & Q2 & $47 / 9673$ & 0.93 & $0.62,1.41$ & & $\mathrm{~T} 1$ & 2/446 & 1.24 & $0.31,5.01$ & & Q2 & $44 / 9674$ & 0.85 & $0.56,1.29$ & \\
\hline & Q3 & 40/9684 & 0.77 & $0.50,1.19$ & & T2 & $0 / 445$ & 0 & 0 & & Q3 & $41 / 9683$ & 0.77 & $0.51,1.18$ & \\
\hline & Q4 & $33 / 9681$ & 0.65 & $0.41,1.03$ & & T3 & $4 / 446$ & $2 \cdot 17$ & $0.80,5 \cdot 86$ & & Q4 & 34/9682 & 0.65 & $0.42,1.03$ & \\
\hline \multirow[t]{5}{*}{$\mathrm{Se}$} & Continuous & $167 / 38613$ & 0.92 & $0.85,1.00$ & 0.04 & Users v. non-users & $10 / 3280$ & 0.72 & $0.38,1.36$ & 0.3 & Continuous & $167 / 38613$ & 0.92 & $0.86,0.99$ & 0.03 \\
\hline & Q1 & $55 / 9617$ & 1 & Ref. & 0.3 & Non-users & $157 / 35333$ & 1 & Ref. & 0.4 & Q1 & $53 / 9618$ & 1 & Ref. & 0.2 \\
\hline & Q2 & $32 / 9670$ & 0.59 & $0.38,0.92$ & & T1 & $3 / 1068$ & 0.73 & $0.23,2.28$ & & Q2 & $35 / 9664$ & 0.68 & $0.44,1.05$ & \\
\hline & Q3 & $44 / 9659$ & 0.83 & $0.54,1.26$ & & T2 & $2 / 1174$ & 0.41 & $0.10,1.66$ & & Q3 & $45 / 9659$ & 0.88 & $0.58,1.33$ & \\
\hline & Q4 & $36 / 9667$ & 0.71 & $0.45,1 \cdot 12$ & & T3 & $5 / 1038$ & 1.01 & $0.41,2.47$ & & Q4 & 34/9672 & 0.68 & $0.43,1.09$ & \\
\hline
\end{tabular}

Q, quartile; Ref., referent values; $T$, tertiles (tertiles of supplemental intake in users of the corresponding supplement)

* Models were adjusted for age (time-scale), sex, BMI ( $\mathrm{kg} / \mathrm{m}^{2}$, continuous), height (cm, continuous), physical activity (high, moderate, low), smoking status (never smokers, former smokers, smokers), number of cigarette packs per year (continuous), numbers of dietary records (continuous), alcohol intake ( $\mathrm{g} / \mathrm{d}$, continuous), energy intake (without alcohol, g/d, continuous), family history of cancer (yes/no) and educational level ( $<$ high-school degree, $<2$ years after highschool degree, $\geq 2$ years after high-school degree).

† Increments for continuous variables were $1 \mathrm{mg} / \mathrm{d}$ for vitamin $\mathrm{E}, 10 \mathrm{mg} / \mathrm{d}$ for vitamin $\mathrm{C}, \beta$-carotene and $10 \mathrm{\mu g} / \mathrm{d}$ for Se.

‡ Cut-off points for sex-specific quartiles of dietary intakes were 72.8/104.9/143.6 mg/d for vitamin C, 8.4/10.6/13.5 mg/d for vitamin E, 2084.0/3126.5/4568.7 mg/d for $\beta$-carotene, and 52.2/64.2/78.6 $\mu \mathrm{g} / \mathrm{d}$ for Se for women, and 76.9/112.8/ $156.5 \mathrm{mg} / \mathrm{d}$ for vitamin C, 9.4/12.1/15.4 mg/d for vitamin E, 2079.0/3168.2/4677.7 mg/d for $\beta$-carotene, and 61.3/75.0/92.5 $\mu \mathrm{g} / \mathrm{d}$ for Se for men. Cut-off points for sex-specific tertiles of supplemental intakes in users of the corresponding supplement were $8.8 / 32.9 \mathrm{mg} / \mathrm{d}$ for vitamin C, $0.9 / 3.0 \mathrm{mg} / \mathrm{d}$ for vitamin E, 339.0/1052.1 mg/d for $\beta$-carotene and 3.4/9.9 $\mu \mathrm{g} / \mathrm{d}$ for Se for women, and $9.9 / 41.1 \mathrm{mg} / \mathrm{d}$ for vitamin C, $0.8 / 3.3 \mathrm{mg} / \mathrm{d}$ for vitamin E, $328.8 / 1183.6 \mathrm{mg} / \mathrm{d}$ for $\beta$-carotene and 2.9/12.3 $\mu \mathrm{g} / \mathrm{d}$ for Se for men. Cut-off points for sex-specific quartiles of total intakes were 75.7/109.1/151.1 mg/d for vitamin C, 8.5/10.9/14.0 mg/d for vitamin E, 2105.2/3154.9/4623.4 mg/d for $\beta$-carotene and 52.7/65.0/80.0 $\mu \mathrm{g} / \mathrm{d}$ for Se for women, and $78.9 / 115 \cdot 5 / 162.0 \mathrm{mg} / \mathrm{d}$ for vitamin C, $9.5 / 12 \cdot 3 / 15 \cdot 8 \mathrm{mg} / \mathrm{d}$ for vitamin $\mathrm{E}, 2088.5 / 3184.7 / 4713.2 \mathrm{mg} / \mathrm{d}$ for $\beta$-carotene and $61.6 / 75 \cdot 5 / 93.4 \mu \mathrm{g} / \mathrm{d}$ for Se for men. 
Table 3. Associations between Se intakes and digestive cancer risk, stratified by the median of alcohol intake, NutriNet-Santé Cohort (n 38812), France, 2009-2016*

(Hazard ratios (HR) and $95 \%$ confidence intervals)

\begin{tabular}{|c|c|c|c|c|c|}
\hline \multirow[b]{2}{*}{$\mathrm{Se}$} & \multicolumn{5}{|c|}{ Nutrient intake } \\
\hline & Cases/non-cases & $\mathrm{HR} \dagger$ & $95 \% \mathrm{Cl}$ & $P_{\text {trend }} \dagger$ & $P_{\text {interaction }} \ddagger$ \\
\hline Dietary intake (continuous) & & & & & 0.02 \\
\hline Alcohol intake $<$ median & 73/19308 & 0.96 & $0.87,1.07$ & 0.5 & \\
\hline Alcohol intake $\geq$ median & $94 / 19305$ & 0.88 & $0.79,0.99$ & 0.03 & \\
\hline Supplemental intake (users $v$ non-users) & & & & & 0.7 \\
\hline Alcohol intake $<$ median & $73 / 19308$ & 0.56 & $0.13,2.37$ & 0.4 & \\
\hline Alcohol intake $\geq$ median & $94 / 19305$ & 0.90 & $0.38,2 \cdot 12$ & 0.8 & \\
\hline Total intake (continuous) & & & & & 0.01 \\
\hline Alcohol intake $<$ median & 73/19308 & 0.96 & $0.87,1.06$ & 0.4 & \\
\hline Alcohol intake $\geq$ median & $94 / 19305$ & 0.88 & $0.79,0.98$ & 0.02 & \\
\hline
\end{tabular}

* From multivariable Cox proportional hazards models. The median of daily alcohol intake was $3.6 \mathrm{~g} / \mathrm{J}$ for women and $12.4 \mathrm{~g} / \mathrm{J}$ for men. Models were adjusted for age, BMI, height, physical activity, smoking status, number of cigarette packs per year, number of dietary records, alcohol intake, energy intake without alcohol, family history of cancer and educational level.

† HR and $P_{\text {trend }}$ for an increment of $10 \mu \mathrm{g} / \mathrm{d}$ of Se for dietary and total intakes and for users $v$. non-users for supplemental intake.

$\ddagger$ Between nutrient intake and alcohol intake.

Table 4. Associations between vitamin $\mathrm{E}$ intakes and digestive cancer risk, stratified by smoking status, NutriNet-Santé Cohort (n 38812), France, 2009-2016*

(Hazard ratios (HR) and $95 \%$ confidence intervals)

\begin{tabular}{lccccc}
\hline & \multicolumn{3}{c}{ Nutrient intake } \\
\cline { 2 - 6 } Vitamin E & Cases/non-cases & HR $\dagger$ & $95 \% \mathrm{Cl}$ & $P_{\text {trend }} \dagger$ & $P_{\text {interaction }}$ \\
\hline Dietary intake (continuous) & & & & 0.01 \\
$\quad$ Current smokers & $20 / 4302$ & 1.08 & $0.97,1.19$ & 0.2 & \\
$\quad$ Never/former smokers & $147 / 34280$ & 0.94 & $0.89,0.98$ & 0.007 & 0.9 \\
$\quad$ Supplemental intake (users $v$. non-users) & $20 / 4302$ & 0.00 & 0.00 & 1.0 & \\
$\quad$ Current smokers & $147 / 34280$ & 1.04 & $0.64,1.69$ & 0.9 & 0.6 \\
$\quad$ Never/former smokers & $20 / 4302$ & 1.01 & $0.97,1.05$ & 0.8 & \\
$\quad$ Total intake (continuous) & $147 / 34280$ & 0.99 & $0.97,1.02$ & 0.5 & \\
$\quad$ Current smokers & Never/former smokers & & & \\
\hline
\end{tabular}

* From multivariable Cox proportional hazards models. Models were adjusted for age, BMI, height, physical activity, number of cigarette packs per year, number of dietary records, alcohol intake, energy intake without alcohol, family history of cancer and educational level.

† HR and $P_{\text {trend }}$ for an increment of $1 \mathrm{mg} / \mathrm{d}$ of vitamin E for dietary and total intakes and for users $v$. non-users for supplemental intake.

¥ Between nutrient intake and smoking status.

been investigated for many years in experimental studies, providing convincing evidence regarding mechanistic plausibility and mode of action. Antioxidants may notably protect against DNA damage caused by mutagen attacks, enhance DNA repair, inhibit carcinogen formation and activation, help maintain membrane integrity, stimulate the immune system, prevent lipid peroxidation, produce cytotoxic metabolites which have antitumorigenic effects and simulate apoptosis ${ }^{(2,43)}$.

However, evidence from epidemiological studies on human populations is less clear. Several interventional or observational studies and meta-analyses concluded the absence of an association between antioxidant intake and digestive cancer risk ${ }^{(2,3,10-12,16,44)}$. For instance, this was the case in a meta-analysis of supplemental antioxidant intakes and colorectal cancer risk including twenty randomised trials and, thus, 268590 participants $^{(3)}$, and another meta-analysis of fourteen trials on vitamin $\mathrm{E}$ and $\beta$-carotene supplement use and gastrointestinal cancers, which is consistent with our results ${ }^{(2)}$. Recent meta-analyses of observational cohort studies did not find any association between supplemental ${ }^{(10)}$ and dietary and total ${ }^{(11)}$ intakes of vitamins $\mathrm{C}$ and $\mathrm{E}$ and colorectal cancer risk, or vitamin $\mathrm{C}$ intake and pancreatic cancer risk ${ }^{(12)}$.
A meta-analysis of seventy-six cohort studies observed no significant association between dietary vitamin $\mathrm{E}$ intake and stomach cancer risk ${ }^{(16)}$. Similarly, no association was observed between dietary total antioxidant capacity or intakes of selected antioxidants (vitamins $\mathrm{C}$ and $\mathrm{E}$ and $\beta$-carotene) and colorectal cancer risk in 45194 participants of the Italian European Prospective Investigation into Cancer and Nutrition (EPIC) cohort $^{(44)}$.

In contrast, our findings are in line with meta-analyses and prospective studies that have observed inverse associations between antioxidant intakes and digestive cancer risk. The meta-analysis of Fang et al. ${ }^{(16)}$, published in 2015 and including seventy-six cohort studies, showed a significant inverse association between dietary vitamin $\mathrm{C}$ intake and stomach cancer risk, during 3.3-30 years of follow-up investigation. A metaanalysis published in 2015 included four cohort studies and found an association between vitamin $\mathrm{E}$ intake and decreased pancreatic cancer risk $^{(13)}$. In all, two prospective studies including, respectively, 77446 American participants from the Vitamins and Lifestyle (VITAL) cohort, aged 50-76 years, and 23658 participants, aged 40-74 years, from the EPIC-Norfolk cohort investigated the associations between dietary ${ }^{(14,15)}$ 
and supplemental and total ${ }^{(15)}$ intakes of Se and pancreatic cancer risk. They found a significant association between dietary Se intake and decreased pancreatic cancer, whereas no association was observed for supplemental and total intakes ${ }^{(14,15)}$.

The fact that epidemiological findings struggle to confirm mechanistic hypothesis from experimental data suggests that individual factors may interact with antioxidant intakes and make the global picture more complex. In exploratory analyses conducted in the present study we observed a statistically significant interaction between dietary and total Se intakes and alcohol intake. Se intake was more specifically associated with decreased digestive cancer risk in participants with higher alcohol intake (above the sex-specific median). Few prospective studies have evaluated the potential modulation by alcohol intake of the associations between antioxidants and digestive cancer risk and no significant interaction was observed $^{(21,23,24)}$. It can be hypothesised that the antioxidant capacity of Se may counteract the pro-oxidant effect of alcohol, playing an aetiological role in cancer ${ }^{(23)}$.

We also observed a significant interaction between dietary vitamin $\mathrm{E}$ intake and smoking status, with a decreased risk for digestive cancers more specifically observed among never and former smokers. However, the number of current smokers (and, thus, cases in this category) was very limited in this study; thus, caution is needed in interpreting these exploratory results. Relatively few prospective studies have investigated the interaction between antioxidant intake and smoking status on digestive cancer risk ${ }^{(19-23)}$, except for $\beta$-carotene supplements, which has been consistently documented ${ }^{(18)}$. Indeed, it has been recognised that high-dose $\beta$-carotene supplement use in smokers increases lung and, probably, gastric cancer risks ${ }^{(18)}$, through several mechanisms (e.g. shift from antioxidant to pro-oxidant depending on the redox potential of the environment, increase in DNA oxidative damage and modification of p53-related pathways of cell proliferation and apoptosis when cells are exposed to tobacco smoke condensate $\left.{ }^{(45)}\right)$. In the present study, such an interaction has not been detected, maybe because of the limited doses of $\beta$-carotene supplements available on the French market (maximum $4.8 \mathrm{mg} / \mathrm{g}$ ) and, most importantly, the limited number of $\beta$-carotene supplement users, compared to other more widespread antioxidant supplements.

The strengths of our study pertained to its prospective design, the quantitative assessment of dietary intakes from a validated questionnaire and the detailed quantitative assessment of nutritional intake from dietary supplements, based on a composition table that included $>8000$ products available on the French market. Nevertheless, some limitations should be acknowledged. First, analyses could not be conducted separately for the different digestive cancers (except for colorectal cancer) because of a limited number of cases, and the results may be driven by colorectal cancer. Similarly, statistical power was limited in analyses focused on supplemental intakes, because of the moderate number of dietary supplement users. Second, regarding dietary supplement intake, the questionnaire only covered 12 months at the beginning of the follow-up study. An update of these data later during follow-up investigation would improve the precision of exposure assessment. Next, residual confounding cannot be ruled out. It could have been interesting to adjust for fat-mass percentage or sedentary behaviour, but these factors were not available for the whole cohort at baseline. However, analyses were adjusted for a wide range of covariates, thereby limiting potential confusion bias. Finally, caution is needed regarding the extrapolation of these results to the entire French population as this study included volunteers involved in a long-term cohort study investigating the association between nutrition and health, with overall more health-conscious behaviours and a higher socioprofessional and educational level. Thus, unhealthy dietary behaviours may have been underrepresented in this study, which may have weakened the observed associations.

In conclusion, this prospective cohort study suggested that vitamin $\mathrm{C}$, vitamin $\mathrm{E}$ and Se could be inversely associated with digestive cancer risk, in line with mechanistic hypotheses. Associations between antioxidant intakes and digestive cancer risk were driven by dietary intakes, whereas no association was found with supplemental intake. Smoking status and alcohol intake may modulate some of these associations. These results need to be confirmed in future large prospective observational and interventional studies before public health recommendations could be derived. In the meantime, reaching an adequate intake of antioxidants through a balanced diet should be recommended, rather than regular use of dietary supplements, of which long-term effects still need deeper investigation.

\section{Acknowledgements}

The authors thank all the volunteers of the NutriNet-Santé cohort. The authors extend special thanks to Ludivine Ursule, Cédric Agaesse, Claudia Chahine, Anne-Elise Dussoulier and Marion Genest, dietitians, for the elaboration of the dietary supplement composition database. The authors also thank Véronique Gourlet, Nathalie Arnault, Laurent Bourhis, Than Duong Van, Younes Esseddik, Julien Allègre, Fabien Szabo, Roland Andrianasolo and Fatoumata Diallo for their technical contribution to the NutriNet-Santé study.

This project has been conducted in the framework of the French network for Nutrition And Cancer Research (NACRe network). This project was funded by the Cancéropôle Ile de France/Région Ile de France (PhD grants of Mélanie Deschasaux and Philippine Fassier and QUANTICA Emergence project). The NutriNet-Santé study was supported by the following public institutions: Ministère de la Santé, Santé Publique France, Région Ile-de-France (CORDDIM), Institut National de la Santé et de la Recherche Médicale, Institut National de la Recherche Agronomique, Conservatoire National des Arts et Métiers and Universite Paris 13. The funders had no role in the design, implementation, analysis, or interpretation of the data.

The authors' contributions were as follows: M. E., P. F. and M. T. designed the research; S. H. and M. T. conducted the research; M. E. performed statistical analysis; M. T. and P. F. supervised statistical analysis; M. E. and M. T. wrote the paper; M. E., P. F., L. L., R. G., L. Z., M.-P. V., S. H., P. L.-M., N. D.-P., P. G., M. D. and M. T. contributed to the data interpretation and revised each draft for important intellectual content. All authors 
read and approved the final manuscript. M. T. had primary responsibility for the final content.

The authors declare that there are no conflicts of interest.

\section{References}

1. Ferlay J, Soerjomataram I, Ervik M, et al. (2013) GLOBOCAN 2012 v1.0, Cancer Incidence and Mortality Worldwide, IARC CancerBase no. 11. Lyon: International Agency for Research on Cancer. http://globocan.iarc.fr (accessed April 2017).

2. Bjelakovic G, Nikolova D, Simonetti RG, et al. (2004) Antioxidant supplements for prevention of gastrointestinal cancers: a systematic review and meta-analysis. Lancet 364, 1219-1228.

3. Pais R \& Dumitrascu DL (2013) Do antioxidants prevent colorectal cancer? A meta-analysis. Rom J Intern Med 51, 152-163.

4. Schwingshackl L, Boeing H, Stelmach-Mardas M, et al. (2017) Dietary supplements and risk of cause-specific death, cardiovascular disease, and cancer: a systematic review and metaanalysis of primary prevention trials. Adv Nutr 8, 27-39.

5. World Cancer Research Fund \& American Institute for Cancer Research (2010) Food, Nutrition, Physical Activity and the Prevention of Colorectal Cancer: Continuous Project Update. Washington, DC: AIRC.

6. World Cancer Research Fund \& American Institute for Cancer Research (2012) Food, Nutrition, Physical Activity and the Prevention of Pancreatic Cancer: Continuous Project Update. Washington, DC: AIRC.

7. World Cancer Research Fund \& American Institute for Cancer Research (2015) Food, Nutrition, Physical Activity and the Prevention of Stomach Cancer: Continuous Project Update. Washington, DC: AIRC.

8. World Cancer Research Fund \& American Institute for Cancer Research (2015) Food, Nutrition, Physical Activity and the Prevention of Liver Cancer: Continuous Project Update. Washington, DC: AIRC.

9. World Cancer Research Fund \& American Institute for Cancer Research (2016) Food, Nutrition, Physical Activity and the Prevention of Oesophageal Cancer: Continuous Project Update. Washington, DC: AIRC.

10. Heine-Broring RC, Winkels RM, Renkema JM, et al. (2015) Dietary supplement use and colorectal cancer risk: a systematic review and meta-analyses of prospective cohort studies. Int J Cancer 136, 2388-2401.

11. Liu Y, Yu Q, Zhu Z, et al. (2015) Vitamin and multiple-vitamin supplement intake and incidence of colorectal cancer: a meta-analysis of cohort studies. Med Oncol 32, 434.

12. Hua YF, Wang GQ, Jiang W, et al. (2016) Vitamin C intake and pancreatic cancer risk: a meta-analysis of published case-control and cohort studies. PLOS ONE 11, e0148816.

13. Peng L, Liu X, Lu Q, et al. (2015) Vitamin E intake and pancreatic cancer risk: a meta-analysis of observational studies. Med Sci Monit 21, 1249-1255.

14. Banim PJ, Luben R, McTaggart A, et al. (2013) Dietary antioxidants and the aetiology of pancreatic cancer: a cohort study using data from food diaries and biomarkers. Gut $\mathbf{6 2}$, 1489-1496.

15. Han X, Li J, Brasky TM, et al. (2013) Antioxidant intake and pancreatic cancer risk: the Vitamins and Lifestyle (VITAL) study. Cancer 119, 1314-1320.

16. Fang X, Wei J, He X, et al. (2015) Landscape of dietary factors associated with risk of gastric cancer: A systematic review and dose-response meta-analysis of prospective cohort studies. Eur J Cancer 51, 2820-2832.
17. Touvier M, Kesse E, Clavel-Chapelon F, et al. (2005) Dual association of beta-carotene with risk of tobacco-related cancers in a cohort of French women. J Natl Cancer Inst 97, $1338-1344$.

18. Latino-Martel P, Cottet V, Druesne-Pecollo N, et al. (2016) Alcoholic beverages, obesity, physical activity and other nutritional factors, and cancer risk: a review of the evidence. Crit Rev Oncol Hematol 99, 308-323.

19. Hansen RD, Albieri V, Tjonneland A, et al. (2013) Effects of smoking and antioxidant micronutrients on risk of colorectal cancer. Clin Gastroenterol Hepatol 11, 406-415.

20. Heinen MM, Verhage BA, Goldbohm RA, et al. (2012) Intake of vegetables, fruits, carotenoids and vitamins $\mathrm{C}$ and $\mathrm{E}$ and pancreatic cancer risk in The Netherlands Cohort Study. Int J Cancer 130, 147-158.

21. Hughes DJ, Fedirko V, Jenab M, et al. (2015) Selenium status is associated with colorectal cancer risk in the European Prospective Investigation of Cancer and Nutrition cohort. Int J Cancer 136, 1149-1161.

22. Kurahashi N, Inoue M, Iwasaki M, et al. (2009) Vegetable, fruit and antioxidant nutrient consumption and subsequent risk of hepatocellular carcinoma: a prospective cohort study in Japan. Br J Cancer 100, 181-184.

23. Michels KB, Edward G, Joshipura KJ, et al. (2000) Prospective study of fruit and vegetable consumption and incidence of colon and rectal cancers. J Natl Cancer Inst 92, 1740-1752.

24. Albanes D, Malila N, Taylor PR, et al. (2000) Effects of supplemental alpha-tocopherol and beta-carotene on colorectal cancer: results from a controlled trial (Finland). Cancer Causes Control 11, 197-205.

25. Shibata A, Paganini-Hill A, Ross RK, et al. (1992) Intake of vegetables, fruits, beta-carotene, vitamin $\mathrm{C}$ and vitamin supplements and cancer incidence among the elderly: a prospective study. Br J Cancer 66, 673-679.

26. Zhang W, Shu XO, Li H, et al. (2012) Vitamin intake and liver cancer risk: a report from two cohort studies in China. $J$ Natl Cancer Inst 104, 1173-1181.

27. Skeie G, Braaten T, Hjartaker A, et al. (2009) Use of dietary supplements in the European prospective investigation into cancer and nutrition calibration study. Eur J Clin Nutr 63, Suppl. 4, S226-S238.

28. Hercberg S, Castetbon K, Czernichow S, et al. (2010) The Nutrinet-Sante Study: a web-based prospective study on the relationship between nutrition and health and determinants of dietary patterns and nutritional status. BMC Public Health 10, 242.

29. Vergnaud AC, Touvier M, Mejean C, et al. (2011) Agreement between web-based and paper versions of a sociodemographic questionnaire in the NutriNet-Sante study. Int J Public Health 56, 407-417.

30. Lassale C, Peneau S, Touvier M, et al. (2013) Validity of webbased self-reported weight and height: results of the NutrinetSante study. J Med Internet Res 15, e152.

31. Touvier M, Mejean C, Kesse-Guyot E, et al. (2010) Comparison between web-based and paper versions of a self-administered anthropometric questionnaire. Eur J Epidemiol 25, 287-296.

32. International Physical Activity Questionnaire Group (2005) Guidelines for Data Processing and Analysis of the International Physical Activity Questionnaire (IPAQ). International Physical Activity Questionnaire Group.

33. Ainsworth BE, Haskell WL, Whitt MC, et al. (2000) Compendium of physical activities: an update of activity codes and MET intensities. Med Sci Sports Exerc 32, 9 Suppl., S498-S504.

34. Lassale C, Castetbon K, Laporte F, et al. (2015) Validation of a Web-based, self-administered, non-consecutive-day dietary record tool against urinary biomarkers. Br J Nutr 113, 953-962. 
35. Lassale C, Castetbon K, Laporte F, et al. (2016) Correlations between fruit, vegetables, fish, vitamins, and fatty acids estimated by web-based nonconsecutive dietary records and respective biomarkers of nutritional status. $J$ Acad Nutr Diet 116, 427-438.

36. Touvier M, Kesse-Guyot E, Mejean C, et al. (2011) Comparison between an interactive web-based self-administered $24 \mathrm{~h}$ dietary record and an interview by a dietitian for large-scale epidemiological studies. Br J Nutr 105, 1055-1064.

37. Le Moullec N, Deheeger M, Preziosi P, et al. (2016) Validation du manuel photo utilisé pour l'enquête alimentaire de l'étude SU.VI. MAX. (Validation of the food portion size booklet used in the SU. VI.MAX study) (in French). Cah Nutr Diet 1996 31, 158-164.

38. Arnault N, Caillot L, Castetbon K, et al. (2013) Table de composition des aliments, étude NutriNet-Santé (Food Composition Table, NutriNet-Santé Study). Paris: Les éditions INSERM/Economica (in French).

39. Black AE (2000) Critical evaluation of energy intake using the Goldberg cut-off for energy intake:basal metabolic rate. A practical guide to its calculation, use and limitations. Int J Obes Relat Metab Disord 24, 1119-1130.
40. Pouchieu C, Andreeva VA, Peneau S, et al. (2013) Sociodemographic, lifestyle and dietary correlates of dietary supplement use in a large sample of French adults: results from the NutriNet-Sante cohort study. Br J Nutr 110, 1480-1491.

41. World Health Organization (2010) International Classification of Diseases and Related Health Problems, 10th revision. Boulogne-Billancourt: WHO.

42. The French National Cancer Institute (2016) Estimated incidence and mortality by age group and cancer location in 2012. lesdonnees.e-cancer.fr (accessed August 2016).

43. Reiter E, Jiang Q \& Christen S (2007) Anti-inflammatory properties of alpha- and gamma-tocopherol. Mol Aspects Med 28, 668-691.

44. Vece MM, Agnoli C, Grioni S, et al. (2015) Dietary total antioxidant capacity and colorectal cancer in the Italian EPIC cohort. PLOS ONE 10, e0142995.

45. Palozza P, Serini S, Di NF, et al. (2004) Beta-carotene exacerbates DNA oxidative damage and modifies p53-related pathways of cell proliferation and apoptosis in cultured cells exposed to tobacco smoke condensate. Carcinogenesis 25, 1315-1325. 